\title{
Evaluation of Serum Levels of Lipid Profile in Patient with Chronic Periodontitis Patients
}

\author{
Zainab J. Raheem \\ ${ }^{1}$ Assistant Lecturer, Department of Periodontics, College of Dentistry, Baghdad University
}

\begin{abstract}
Background: Chronic Periodontitis, a prevalent oral disease, chronic infections., has been linked to several systemic health changes, like changing in lipid metabolism. Aims of the study were to evaluate the serum levels of lipid profile (total cholesterol, triglycerides high density lipoproteins, low density lipoproteins and very low density lipoproteins. In study and control groups and compare between them. Also, test the correlation between the serum levels of lipid profile with clinical periodontal parameters. Materials and Methods:50 subjects, males and females were included in this study with age range (35-50) years old, they were divided into two groups [CP group: chronic periodontitis group (25 patients)] andcontrol group: (25 systemically healthy subjects, have healthy periodontium). Periodontal health status was determined by measuring the following clinical periodontal parameters (Plaque index (PL.I), Gingival index (GI), Bleeding on probing (BOP), Probing pocket depth (PPD) and Clinical attachment level (CAL)).Serum levels oflipid profile were measured by Enzymatic colorimetric method. Results: The results showed that mean values of (TC, TGL, HDL, LDL and VLDL) were high in CPgroup than control group with highly significant difference at $P<0.001 . t h e r e$ were $T C$ showed positive, strong and significant with (PLI, PPD and CAL), while with (GL and BOP score 1) showedpositive but non-significant correlation. The serum levels of TGL showed positive weak non-significant with (PLI, BOPsore1, and PPD, CAL) and negative correlation with GI. HDL, LDL and VLDL showed positive but non-significant correlation with clinical periodontal parameters except the correlation between LDL and PPD was positive, strong and significant. Conclusion: The elevated levels of serum lipid profile which were observed in chronic periodontitis patients suggest an increased risk for Cardiovascular disease in chronic periodontitis patients.
\end{abstract}

Keywords: Chronic periodontitis, serum lipid level, hyperlipidaemia, cholesterol, triglyceride, HDL, LDL.

\section{Introduction}

Chronic periodontitis is a bacterial infectious disease that affects the supporting structures of teeth leading to transient and recurrent bacteremia which lead to many local and systemic inflammatory responses. Periodontitis is a common oral disease in adults that affect many systemic health changes; involving altering lipid metabolism [1].

Lipids may modify immune response, by altering the macrophages cell membrane, interfering with enzyme systems and proinflammatory cytokines, such as tumor necrosis factor-alpha (TNF-a) and interleukin (IL)-1b[2], which are associated with periodontal disease[3].

Many studies revealed an association betweenperiodontitis and hyperlipidemia. Some studies [4-7] report that patients with hyperlipidemia (diagnosed by physicianhad higher periodontal parameters compared to systemically healthy controls.

The purpose of this study was to show the relation between chronic periodontitis and serum level of total cholesterol (TC), triglycerides (TGL) high density lipoproteins (HDL), low density lipoproteins (LDL) and very low-density lipoproteins (VLDL).

\section{Subjects, Materials and Methods}

In this study Fifty (50) subjects, males and females, aged (35-55) years old were recruited in this study. They were from attendants patients were seeking periodontal treatment in department of periodontics at Teaching Hospital College of Dentistry, Baghdad University. All the participants were informed about the aim of these investigations and consented to its protocol. The subjects were divided into: $\mathrm{CP}$ group consists of thirty patients diagnosed to have chronic periodontitis and didn't have history of any systemic diseases. Chronic periodontitis in patients was defined as the presence of at least four sites with PPD of $\geq(4) \mathrm{mm}$ and clinical attachment loss of $\geq(1-2) \mathrm{mm}$, this made according to the international classification system for PD[8).Control group consists of twenty patients with clinically healthy Periodontium this was defined by GI scores $<0.5$ [9] with no pockets or clinical attachment loss and no history of any systemic diseases. The body mass index of all 50 participants were assessed depending on the criteria by NietoGarcia et al.[10].Any participants had BMI more than 25 excluded from the study, also the other Exclusion criteria were included history of other chronic, systemic diseases with known associations with PD as diabetes mellitus, Rheumatoid Arthritis, etc. Smoker. Medication (antiinflammatory or antimicrobial therapy) within previous 3 months. Periodontal treatment within previous 3 months. Pregnancy. Contraceptive pills. Clinical periodontal parameters examination was doneby using Michigan $\mathrm{O}$ periodontal probe on four surfaces (mesial, buccal/ labial, distal and lingual/ palatal) of all teeth except third molar, all subjects must have at least 20 teeth. The collected data include assessment of (PL.I)[11](GI)[9]BOP[12]PPD[8] CAL[8]. After the clinical periodontal parameters examination $.5 \mathrm{ml}$ venous blood was collected from study and control groups after a minimum twelve-hour fast, for the biochemistry analysis of the serum lipid profile levels $\{$ TC,TGL,HD,LDL,]\}.Enzymatic colorimetric method using (AGAPPE, Indea) kit. VLDL was assessed according to the formula in which VLDL=TG/5).Normal values were taken as follows 


\section{International Journal of Science and Research (IJSR) \\ ISSN (Online): 2319-7064}

Index Copernicus Value (2016): 79.57 | Impact Factor (2015): 6.391

\begin{tabular}{|l|l|}
\hline Enzyme & Normal range \\
\hline TC & $150-220 \mathrm{mg} / \mathrm{dL}$ \\
\hline \multirow{2}{*}{ TGL } & Male $: 60-165 \mathrm{mg} / \mathrm{dL}$ \\
\cline { 2 - 2 } & Female $: 40-140 \mathrm{mg} / \mathrm{dL}$ \\
\hline \multirow{2}{*}{ LDL } & Male $: 35-80 \mathrm{mg} / \mathrm{dL}$ \\
\cline { 2 - 2 } & Female $: 42-88 \mathrm{mg} / \mathrm{dL}$ \\
\hline \multirow{3}{*}{ HDL } & Desirable $<130 \mathrm{mg} / \mathrm{dL}$ \\
\cline { 2 - 2 } & Borderline High Risk for CHD130-159 mg/dL \\
\cline { 2 - 2 } & High Risk for CHD $>160 \mathrm{mg} / \mathrm{dL}$. \\
\hline VLDL & $2-30 \mathrm{mg} / \mathrm{dL}$ \\
\hline
\end{tabular}

Statistical analysis was assessed using Mean, standard deviation (SD), Mean of percentage T-test, and Pearson coefficient of correlation).

\section{Result}

Table (1) showed Descriptive statistics of the clinical periodontal parameters (PLI, GI, PPD, CAL and BOP sore 1) for study (CP) and control groups. This study showed that serum levels of lipid profile were higher in chronic periodontitis patients than control group with highly significant difference between the groups as demonstrated in table (2). The serum levels ofTCwas (219.48 \pm 31.02),TGL(113.85 \pm 11.87$), \operatorname{HDL}(45.36 \pm 6.23), \mathrm{LDL}(152.25$ $+9.61)$, VLDL $(30.45 \pm 1.92)$ in CP group while in Control group were $\{(155.32 \pm 12.21),(89.03 \pm 15.58),(42.41 \pm 1.49)$, (76.25+13.82), (15.25 \pm 2.76$)\}$ respectively. Table (3) reveled the correlation between the serum levels of lipid profile and clinical periodontal parameters in $\mathrm{CP}$ group, serum level of TC showed positive, strong and significant with (PLI, PPD and CAL), while with (GL and BOP score 1) showed positive but non-significant correlation. The serum levels of TGL showed positive weak non-significant with (PLI, BOPsore1, PPD, CAL) and negative correlation with GI. HDL, LDL and VLDL showed positive but nonsignificant correlation with clinical periodontal parameters except the correlation between LDL and PPD was positive, strong and significant.

Table 1: Descriptive statistics of the clinical periodontal parameters for study groups

\begin{tabular}{|c|c|c|c|c|c|c|c|c|c|}
\hline \multirow{2}{*}{ Groups } & \multicolumn{2}{|c|}{ PlI } & \multicolumn{2}{c|}{ GI } & \multicolumn{2}{c|}{ PPD } & \multicolumn{2}{c|}{ CAL } & BOP \\
\cline { 2 - 10 } & Mean & \pm SD & Mean & \pm SD & Mean & \pm SD & Mean & \pm SD & Percentage Score 1 \\
\hline CP & 1.73 & \pm 0.6 & 1.81 & \pm 0.35 & 5.06 & \pm 0.91 & 3.09 & \pm 0.98 & $53.72 \%$ \\
\hline Control & 0.8 & \pm 0.09 & 0.74 & \pm 0.15 & & & & & \\
\hline
\end{tabular}

Table 2: Descriptive statistics of the serum levels of lipid profile for study groups with Comparison between the groups

\begin{tabular}{|c|c|c|c|c|c|c|c|}
\hline \multirow{2}{*}{ Variable } & \multicolumn{2}{|c|}{ CP group } & \multicolumn{2}{|c|}{ Control group } & \multirow{2}{*}{ t-test } & \multirow{2}{*}{-value } & \multirow{2}{*}{ Sig. } \\
\cline { 2 - 8 } & Mean & $\pm \mathrm{SD}$ & Mean & $\pm \mathrm{SD}$ & & & \\
\hline$T G L(m g \backslash d l)$ & 219.48 & \pm 31.02 & 155.32 & \pm 12.21 & 9.63 & $<0.001$ & $H S$ \\
\hline$T G L(m g \backslash d l)$ & 113.85 & \pm 11.87 & 89.03 & \pm 15.58 & 6.337 & $<0.001$ & $H S$ \\
\hline$H D L(m g \backslash d l)$ & 45.36 & \pm 6.23 & 42.41 & \pm 1.49 & 22.56 & $<0.001$ & $H S$ \\
\hline$L D L(m g \backslash d l)$ & 152.25 & \pm 9.61 & 76.25 & \pm 13.82 & 2.3 & 0.02 & $S$ \\
\hline$V L D L(m g \backslash d l)$ & 30.45 & \pm 1.92 & 15.25 & \pm 2.76 & 6.34 & $<0.001$ & $H S$ \\
\hline
\end{tabular}

Table 3: Pearson correlation between serum levels of lipid profile and clinical periodontal parameters at study group

\begin{tabular}{|c|c|c|c|c|c|c|}
\hline Variables & & PLI & GI & PPD & BOP1 & CAL \\
\hline \multirow{2}{*}{ TC } & r & 0.564 & 0.209 & 0.729 & 0.057 & 0.915 \\
\cline { 2 - 7 } & P value & 0.003 & 0.316 & $<0.001$ & 0.78 & $<0.001$ \\
\cline { 2 - 7 } & Sig. & S & NS & HS & NS & HS \\
\hline \multirow{3}{*}{ TGL } & r & 0.235 & -0.173 & 0.0185 & 0.333 & 0.3 \\
\cline { 2 - 7 } & P value & 0.258 & 0.408 & 0.93 & 0.1 & 0.145 \\
\hline \multirow{2}{*}{ HDL } & Sig. & NS & NS & NS & NS & NS \\
\cline { 2 - 7 } & r & 0.0831 & 0.142 & 0.0511 & -0.12 & 0.374 \\
\hline \multirow{2}{*}{ PDL value } & 0.69 & 0.498 & 0.808 & 0.57 & 0.065 \\
\hline & Sig. & NS & NS & NS & NS & NS \\
\hline & r & 0.292 & 0.0166 & 0.398 & 0.004 & 0.1537 \\
\cline { 2 - 7 } & P value & 0.156 & 0.937 & 0.048 & 0.98 & 0.462 \\
\hline \multirow{2}{*}{ VLDL } & Sig. & NS & NS & S & NS & NS \\
\cline { 2 - 7 } & P value & -0.17 & 0.0188 & -0.254 & 0.004 & 0.0577 \\
\cline { 2 - 7 } & Sig. & NS & 0.928 & 0.22 & 0.98 & 0.784 \\
\hline
\end{tabular}

\section{Discussion}

The present study demonstrated higher serum levels of lipid profile in $\mathrm{CP}$ group than in healthy subjects. Many studies address a relation between chronic periodontitis and serum levels of lipid profile [13-19] and found elevated serum levels of lipid profile in CP. Each of these studies has their own specifications such as definition of periodontal disease definition, study design and the assay for serum lipid levels assessment.

Periodontal disease is the second most common oral disease that is initiated by specific species of pathogenic microorganisms in the dental biofilm. Inflammation is the central cause for tissue destruction that occurs in chronic periodontitis. In the periodontal tissues, the inflammatory process starts with the penetration of the various bacterial toxins and enzymes through the lining epithelium. The inflammatory process becomes chronic when the pathogenic microorganisms continue to grow and cannot be eliminated by the host response. Thus, the inflammatory reaction persist leading to damage to the periodontal tissues. Chronic periodontitis is thus characterized by persistent gingival inflammation, fibrosis, and loss of periodontal tissues. If not treated, it results in apical migration of the junctional epithelium and destruction of the periodontal attachment apparatus including the alveolar bone [20-21]

The two possible mechanisms suggested by which this can occur are by direct migration and colonization of the pathogenic microorganisms to distant organs, leading to an inflammatory reaction at sites distant from the point of infection, and also the systemic inflammation as a result of metastatic periodontal inflammation[22].

\section{Volume 6 Issue 12, December 2017}




\section{International Journal of Science and Research (IJSR) \\ ISSN (Online): 2319-7064}

Index Copernicus Value (2016): 79.57 | Impact Factor (2015): 6.391

Thus, the present study was conducted to evaluate the lipid profile (TC, TGL, HDL, LDL and VLDL) of the groups to understand the association between chronic periodontitis and dyslipidemia.

Iacopino et al. showed any local inflammation causes raised in systemic proinflammatory levels will be a potential factor of lipid imbalance, as in chronic periodontitis causes raising in systemic levels of the IL- $1 \beta$ and TNF- $\alpha$ which promote the lever to biosynthesis of cholesterol [21]. Fentoglu et al. established the accuracy of this fact by demonstrating the association between IL-1 $\beta$, IL- 6 and TNF- $\alpha$ levels and TC/HDL ratio [23]. On the other hand, the periodontal pathogens and their systemic by-products have direct effect by elicitation an immune-inflammatory response and changes in the lipid metabolism, leading to higher levels of VLDL and LDL and decrease in the level of HDL increasing LDL oxidation and the expression of receptors for LDL involved in the control of plasma lipid levels [24, 25]. In periodontitis there were increased in production of ROS that would contribute to an increase in the process of lipid peroxidation. These Different mechanisms have been proposed above could be explained the elevated serum levels of lipid profile in $\mathrm{CP}$ group.

As chronic periodontitis its chronic innature with local and systemic immunologichost responses, there were sustained rise in systemic levels of the pro-inflammatory cytokines that would be led to abnormal serum lipid levels and that might explain the positive correlation between serum levels of lipid profile and clinical periodontal parameters as with sever periodontal destruction increased in systemic levels of inflammatory cytokines which in return effect on lipid perioxidation.

In this study the exact mechanism of association between chronic periodontitis and elevated serum levels of lipid profile was not clarified and it needs to be further explored ,beside that the etiology of hyperlipidaemia is multifactorial ,Therefore, several factors could affect the result, specially high serum lipid profile levels as an inappropriate dietary regimen being included in the study. Although, in our study, overweight and obese participants were excluded this might minimizes the possibility of participants with an inappropriate dietary regimen being enrolled in the study.

\section{References}

[1] Ana Cristina Posch Machado; Maria Rozeli de Souza Quirino; Luiz Fernando Costa Nascimento. Relation between chronic periodontal disease and plasmatic levels of triglycerides, total cholesterol and fractions. Braz Oral Res 2005; 19(4):284-9.

[2] Cutler CW, Shinedling EA, Nunn M, Jotwani R, Kim BO,Nares S, et al. Association between periodontitis and hiperlipidemia:cause or effect? J Periodontol 1999; 70:1429-34.

[3] .Losche W, Karapetow F, Pohl A, Pohl C, Kocher T. Plasma lipid and blood glucose levels in patients with destructive periodontal disease. J ClinPeriodontol 2000;27:537-41.

[4] Noack B, Jachmann I, Roscher S, et al. Metabolicdiseases and their possible link to risk indicators ofperiodontitis. J Periodontol 2000;71:898903.

[5] Awartani F, Atassi F. Evaluation of periodontal statusin subjects with hyperlipidemia. J Contemp Dent Pract2010; 11:33-40.

[6] Chu X, Newman J, Park B, Nares S, Ordonez G,Iacopino AM. In vitro alteration of macrophage phenotypeand functions by serum lipids. Cell Tissue Res 1999; 296:331-337.

[7] Heasman PA, Collins JG, Offenbacher S. Changes Increvicular fluid levels of interleukin-1beta, leukotrieneB4, prostaglandin E2, thromboxane B2, and tumour necrosis factor alpha in experimental gingivitis in humans. J Periodontal Res 1993;28:241-247.

[8] American Academy of Periodontology (AAP).Severity of chronic periodontitis. Annals of Periodontology, 1999: page 38.

[9] Löe, H. The Gingival Index, the Plaque Index and the Retention Index Systems.JournalofPeriodontology, 1967;38(6):610-616.

[10] Nieto-García FJ1, Bush TL, Keyl PM, Body mass definitions of obesity: sensitivity and specificity using self-reported weight and height. Epidemiology. 1990 Mar;1(2):146-52.

[11] Silness J, Löe H. Correlation between oral hygiene and periodontal condition. ActaOdontolScand, 1964; 22: 121-135.

[12] Newbrun E.Indices to measure gingival bleeding. Journal Periodontology, 1996; 67(6):555-561.

[13] Lee JB, Yi HY, Bae KH. The association between periodontitis and dyslipidemia based on the Fourth Korea National Health and Nutrition Examination Survey. J Clin Periodontol. 2013;40:437-42. [PubMed]

[14] Deepu Mathews Panickal, Prashanth Evuru, Jeethu John Jerry, Little Mahendra, Sandhya Cherukuri, Jaideep MahendraIJCRR.Estimation of serum lipid levels in chronic periodontitis patients: Acase-control study. 2016; 8(8): 23-26.

[15]Ferial Taleghani, Mahmoud Shamaei, Masoud Shamaei Acta Medica Iranica Association between Chronic Periodontitis and Serum Lipid Levels .2010. 48(1):4750.

[16] V. Saravanan, P. L. Ravishankar, Pradeep Kumar, K. Rajapandian, V. Kalaivani, and M. Prem Blaisie RajulaEstimation of Serum Triglycerides, Serum Cholesterol, Total Protein, IgG Levels in Chronic Periodontitis Affected Elderly Patients: A Cross-Sectional Study.J Int Soc Prev Community Dent. 2017 Mar-Apr; 7(2): 120 124.

[17]-Lal V, Dubey D, Rath SK, Lohra P. Effect of chronic periodontal infection on systemic lipid profile: A clinical and biochemical study. J Int Clin Dent Res Organ 2015; 7:106-10.

[18] R.M. Sandi,1 K.G. Pol,2 P. Basavaraj,3 Nitin Khuller,4 and Shilpi SinghJ Clin Diagn Res.Association of Serum Cholesterol, Triglyceride, High and Low Density Lipoprotein (HDL and LDL) Levels in Chronic Periodontitis Subjects with Risk for Cardiovascular Disease (CVD): 2014 Jan; 8(1): 214-216.

[19] HamissiJ,ShahsavaraniMT,ShahsavaraniH,SayahpourS, HamissiH. A comparison of serum lipid level between patients with periodontitis and healthy individual.Periodontol Implant Dent. 2010; 2:29-32.

\section{Volume 6 Issue 12, December 2017}




\section{International Journal of Science and Research (IJSR) \\ ISSN (Online): 2319-7064}

Index Copernicus Value (2016): 79.57 | Impact Factor (2015): 6.391

[20].Biju Thomas, Rajendra B. Prasad,1 Sucheta Shetty,2 and R. Vishakh. Comparative Evaluation of the Lipid Profile in the Serum of Patients with Type II Diabetes Mellitus and Healthy Individuals with Contemp Clin Dent. 2017 Jan-Mar; 8(1): 96-101. 101.

[21] Iacopino AM, Cutler CW. Pathophysiologic relationships between periodontitis and systemic diseases: Recent concepts involving serum lipids. J Periodontal. 2000; 71:1375-84. [Pub Med].

[22] Hayashi C, Gudino CV, Gibson FC, 3rd, Genco CA. Review: Pathogen-induced inflammation at sites distant from oral infection: Bacterial persistence and induction of cell-specific innate immune inflammatory pathways. Mol Oral Microbiol. 2010; 25:305-16.

[23] Fentoglu O, Bozkurt FY: The bi-directional relationship between periodontal disease and hyperlipidemia. Eur J Dent 2008; 2: 142 - 146.

[24] Maekawa T, Takahashi N, Tabeta K et al. Chronic oral infection with Porphyromonas gingivalis accelerates atheroma formation by shifting the lipid profile. PLoS ONE 6(5), e20240 (2011).

[25] Fentoglu O, Koroglu BK, Hicyilmaz $\mathrm{H}$ et al. Proinflammatory cytokine levels in association between periodontal disease and hyperlipidaemia. J. Clin. Periodontol. 38(1), 8-16 (2011)

Volume 6 Issue 12, December 2017

www.ijsr.net

Licensed Under Creative Commons Attribution CC BY 